\title{
As multisséries no Campo de Arraias-TO: memórias
}

Jocyléia Santana dos Santos $^{1}$, Samara Caldas Franco ${ }^{2}$

${ }^{1}$ Universidade Federal do Tocantins - UFT. Programa de Pós-Graduação em Educação. Avenida NS 15 ACLNO 14 Plano Diretor Sul. Palmas - TO. Brasil. jocyleiasantana@gmail.com. ${ }^{2}$ Universidade Federal do Tocantins UFT.

\begin{abstract}
RESUMO. A pesquisa investiga quais as dificuldades enfrentadas pelos educadores e os educandos que vivenciam a realidade das classes multisseriadas nas escolas da área rural do município de Arraias-TO. A metodologia utilizada foi a proposta pela história oral que consiste na realização de entrevista com os sujeitos envolvidos. Neste caso, foram entrevistados professores e alunos que vivem no contexto das classes multisseriadas no município mencionado. Cerca de 1,3 milhões de alunos estudam em classes multisseriadas do campo no Brasil. A partir do depoimento de professores e alunos, alguns aspectos ganham destaque: falta de formação específica para o docente atuar na multisseriação, questão que afeta a qualidade do ensino; ausência de um currículo voltado também para a realidade do campo, e a falta de infraestrutura física. Estas condições implicam em resultados negativos para a modalidade de Educação no Campo. É necessário construir uma visão positiva do campo, pensar em uma formação inicial e continuada que reverta a visão negativa que se tem do campo com políticas de formação sintonizadas com a dinâmica social específica, onde está implícita a afirmação de direitos à terra, à cultura e identidade e à educação.
\end{abstract}

Palavras-chave: Educação no Campo, Classe Multisseriada, Formação de Professores, História Oral. 


\title{
The multiseries in Campo de Arraias - TO: memories
}

\begin{abstract}
The research investigates the difficulties faced by educators and learners who experience the reality of the multisite classes in rural schools in the municipality of ArraiasTO. The methodology used was the one proposed by the oral history that consists in the accomplishment of an interview with the subjects involved. In this case, we interviewed teachers and students who live in the context of the multi-series classes in the mentioned municipality. About 1.3 million students study in multisite countryside classes in Brazil. From the testimony of teachers and students, some aspects are highlighted: lack of specific training for the teacher to work in the multiseriate, an issue that affects the quality of teaching; absence of a curriculum also focused on the reality of the countryside, and the lack of physical infrastructure. These conditions imply negative results for the education modality in the Rural Education. It is necessary to construct a positive vision of the field, to think of an initial and continuous formation that reverses the negative view that has of the field with policies of formation tuned to the specific social dynamic, where the affirmation of rights to the land, the culture and identity and education.
\end{abstract}

Keywords: Countryside School, Multisserial Class, Teacher Training. 


\section{Las multiserias en el Campo de Arraias- TO: memories}

RESUMEN. La investigación investiga cuáles son las dificultades enfrentadas por los educadores y los educandos que vivencian la realidad de las clases multiserias en las escuelas del área rural del municipio de Arraias-TO. La metodología utilizada fue la propuesta por la historia oral que consiste en la realización de entrevista con los sujetos involucrados. En este caso, fueron entrevistados profesores y alumnos que viven contexto de las clases multiserias en el municipio mencionado. Cerca de 1,3 millones de alumnos estudian en clases multiseriales del campo en Brasil. A partir del testimonio de profesores y alumnos, algunos aspectos ganan destaque: falta de formación específica para el docente actuar en la multiserción, cuestión que afecta la calidad de la enseñanza; la ausencia de un currículo volcado también para la realidad del campo, y la falta de infraestructura física. Estas condiciones implican en resultados negativos para la modalidad de Educación en el Campo. Es necesario construir una visión positiva del campo, pensar en una formación inicial y continuada que revierta la visión negativa que se tiene del campo con políticas de formación sintonizadas con la dinámica social específica, donde está implícita la afirmación de derechos a la tierra, a la cultura y identidad y educación.

Palabras clave: Educación en el Campo, Clase Multiserial, Formación de Profesores, Historia Oral. 


\section{Introdução}

Este artigo é resultado de estudo feito para a disciplina História, Memória e Educação (HME) do Mestrado em Educação da Universidade Federal do Tocantins, focado nas escolas rurais com classes multisseriadas, localizadas no município de Arraias, sudeste do Estado do Tocantins. A disciplina mencionada propiciou o embasamento teórico para a metodologia utilizada, a história oral. Em conformidade com os procedimentos da área, confeccionou-se um roteiro de entrevistas pré-estabelecido, ouviram-se professores e discentes no que diz respeito as suas trajetórias e percepções sobre o contexto em que vivem e atuam. Transcreveram-se as falas, e, em seguida, obteve-se a autorização para a publicação dos nomes dos entrevistados após a assinatura do Termo de Consentimento Livre e Esclarecido (TCLE).

Diante disso, identificaram-se as dificuldades enfrentadas pelos educadores e os educandos que vivenciam a realidade das classes multisseriadas nas escolas da área rural do município de Arraias-TO. Na HME fez-se um projeto para a construção do artigo com um cronograma explicitando tempo para fundamentação teórica, entrevistas e finalização da pesquisa. Num período de seis meses, realizou-se pesquisa bibliográfica e pesquisa de campo e a consecução do artigo como um exercício final da disciplina HME com a metodologia de historia oral (HO). Utilizou-se principalmente Verena Alberti, que tem um manual sobre a história oral onde conceitua que a $\mathrm{HO}$ “... não é um fim em si mesma, e sim um meio de conhecimento. Seu emprego só se justifica no contexto de uma investigação científica" (Alberti, 2004, p. 29).

$\mathrm{Na}$ pesquisa de campo, primeiro buscou-se entender o que era a multisseriação, na perspectiva de Hage (2010) seria uma reunião de estudantes de várias séries e níveis em uma mesma sala de aula, independente do número de professores responsáveis pela turma. Embora possa acontecer de uma escola ou turma ser multisseriada e ter mais de um professor, no meio rural, contam com apenas um professor como responsável pela condução do trabalho pedagógico, sendo, portanto, unidocente.

Quando se pretende uma educação de qualidade, é preciso que se pense em escolas com educador inserido na realidade, estrutura e condições adequadas para ministrar aulas e remuneração justa, além de formação geral e holística, para multisseriação. A prática educativa deve despertar a consciência dos sujeitos de modo que estes consigam associar sua realidade a outras realidades, construindo assim um novo saber, novas relações. 
A pesquisa permitiu inferir que a realidade das escolas rurais multisseriadas do município não se faz diferente das outras escolas rurais brasileiras. As deficiências, principalmente em relação à estrutura física, se perpetuam. Observou-se que, a Educação no Campo tem tido sucesso e conta com boa vontade e profissionalidade dos professores em oferecer um ensino de qualidade aos alunos.

\section{Educação multisseriada em escolas do campo: breve abordagem teórica}

As classes multisseriadas são uma realidade na Educação do Campo no Brasil já há quase dois séculos. Trata-se da junção de várias séries numa mesma sala e na maioria das vezes com apenas um (a) professor (a).

Segundo Piza e Sena (2001), as escolas multisseriadas são, historicamente, consideradas como de segunda categoria e, o que é pior, sem alternativa de melhoria; por isso, os educadores e os gestores optaram por esquecê-las, esperando que desapareçam como consequência natural do processo de desenvolvimento das sociedades. Porém, o desaparecimento natural não existe na história, trata-se, sempre, de funções sociais que cumprem ou deixam de cumprir para desaparecerem ou para recriarem. Por essa razão, apesar de todas as mazelas e das políticas de substituição promulgadas desde a década de 1980, as escolas multisseriadas vêm resistindo e adentraram o século XXI. Esse fato, no entanto, não se faz presente frequentemente nas pesquisas em história da educação.

Se, no seu nascedouro, as escolas multisseriadas atendiam tanto à população periférica quanto a rural, atualmente elas se concentram somente na zona rural. Menezes e Santos (2002, p. 2), ao desenvolverem o verbete Escolas Multisseriadas, no Dicionário Interativo da Educação Brasileira, escrevem que "acredita-se que a educação no campo esteja relegada a segundo plano, limitandose ao ensino das primeiras letras", afirmando também que estas escolas se constituem predominantemente de classes multisseriadas.

Esta realidade está presente na trajetória educacional brasileira desde o período Imperial, quando além de atender as cidades, principalmente as periferias passaram a atender as escolas rurais da época nesta modalidade. A partir da República, o ensino seriado foi implantado nas escolas urbanas, mas o modelo multisseriado de ensino permaneceu em vigor no campo.

É preciso entender que as escolas multisseriadas não podem ser consideradas como escolas isoladas, pois se trata de um 
ambiente que pode ser rico e potencializador. No entanto, em vez disso, se apresentam escolas com pouca ou nenhuma estrutura física, contribuindo para o desânimo e a evasão escolar.

A inexistência de formação especifica aos professores da multisseriação faz com que o ensino urbano seja implantado no currículo dessas escolas dificultando mais ainda a prática dos educadores dessas classes. Dessa forma, os professores culpam o fracasso do ensino dessas escolas à multisseriação.

De acordo com Barros et al. (2010), as escolas multisseriadas são responsáveis pela iniciação escolar da maioria dos sujeitos que vivem no campo, por isso, torna-se tão urgente sua inclusão nas agendas de discussões da educação brasileira, para que sejam previstos investimentos para enfrentar seus desafios.

$\mathrm{O}$ ensino desenvolvido nessas classes é prejudicado, na maioria das vezes, pelo fato de as escolas não oferecerem uma estrutura física apropriada. Na verdade, em vez de escolas, com prédio próprio, são residências de apenas um cômodo ou dois, no máximo, em contraste com a estrutura das escolas urbanas. Há carência de equipamentos e mobiliários, livros com conteúdos voltados para a realidade rural. Outra questão é que os professores, além de ministrarem aulas em várias séries, se sentem sobrecarregados por ter que assumir outras funções, tais como: faxineiro, merendeiro, secretário, etc.

Os docentes também se sentem desconfortáveis por ter que mudar constantemente de escola e os alunos pela troca diária de professores, por conta da relação de trabalho com o ente municipal, baseada na contratação temporária, e não em concurso público.

Barros et al. (2010) também aponta outras dificuldades enfrentadas pelos professores de classes multisseriadas, uma delas, a organização do processo pedagógico das escolas. Os profissionais, por trabalharem em várias séries ao mesmo tempo, têm que elaborar planos de aula separados para cada série. Assim os professores se sentem perdidos, sem qualquer espaço para realização completa de seus trabalhos, e o tempo se torna pouco para trabalhar com tanta série reunida.

Apesar deste contexto, aparentemente negativo, a educação multisseriada é considerada positiva, educação que ajuda na formação humana, valoriza a identidade campesina e que não pode ser esquecida tanto pelo poder público quanto pelos próprios sujeitos que vivem essa realidade de perto.

Hage (2004) tem inúmeros trabalhos sobre escolas multisseriadas e defende que,

Ao atender os estudantes em seu próprio lugar, em sua própria comunidade, as classes 
multisseriadas podem contribuir enormemente com o processo de permanência dos sujeitos do campo no campo e para com a valorização da identidade cultural dos mesmos (Hage, 2004, p. 4).

As escolas com classes multisseriadas, segundo o autor supramencionado, podem ser consideradas como uma boa alternativa para a Educação do Campo. Portanto, é necessário que os professores dessas escolas tenham formação, para que o seu trabalho tenha mais qualidade e bons resultados. De igual modo, a estrutura física da escola deve ser adequada para que haja um melhor aproveitamento e que o projeto político pedagógico esteja de acordo também com suas necessidades.

\section{Educação do Campo: perspectivas teóricas}

Há uma negatividade do espaço rural, o campo é visto nas palavras de Arroyo (2007) como o lugar do atraso, o outro lugar. A cidade por sua vez, é o espaço civilizatório por excelência, de convívio, sociabilidade e socialização, da expressão da dinâmica política, cultural e educativa, destaca o autor.

O campo é lugar de trabalho duro, de luta diária, cheio de riquezas culturais, de crenças fortíssimas, de histórias de vida que são apagadas pela desconstrução da cultura camponesa no momento em que ela é vista como o quintal ou a extensão da cidade. Por ser visto dessa forma, tudo o que vai para as escolas do campo, é o que sobra das escolas da cidade. É como se o rural não necessitasse de coisas boas, a educação basta apenas acontecer, sem se preocupar com que tipo de ensino está sendo ofertado neste setor ou que tipo de material será usado para que a educação aconteça.

Nesse modelo de educação "a formulação de políticas educativas e públicas, em geral, pensa na cidade e nos cidadãos urbanos como o protótipo de sujeitos de direitos" (Arroyo, 2007, 158). Firma-se nesse sentido a concepção de que a cidade é o modelo a ser seguido, como se o campo não tivesse sua própria identidade, prevalecendo o paradigma de que a educação tanto na cidade quanto no campo deve seguir os mesmos modelos, ou seja, essas duas dimensões sociais possuem as mesmas necessidades, os mesmos costumes, o mesmo modo de vida.

Nota-se assim que, de modo geral, as políticas públicas para a Educação do Campo na contemporaneidade estão ainda muito próximas das já vivenciadas políticas de "educação rural” e do "ruralismo pedagógico" do que representar algo de novo, mais progressista. Principalmente porque a formação profissional dos agricultores para que se mantenham inseridos na produção como 
camponeses, avança pouco, permanecendo a quase totalidade das experiências de Educação do Campo apenas enquanto formas de se ganhar tempo até que o êxodo rural proclamado se complete, em acordo com a uniformização e padronização fomentadas pelo modelo de desenvolvimento adotado em nosso País, centrado no agronegócio e no neoliberalismo.

Fernandes (2006, citado por Gonsaga, 2009) faz um paralelo entre Educação do Campo e educação rural, concluindo que esta se diferencia daquela pelo fato de estar inserida nos princípios do paradigma do capitalismo agrário, tendo como ideal de educação o trabalhador do campo como mero executor de tarefas, não assumindo, portanto, o papel de protagonista neste processo, mas sim de subalterno aos interesses do capital.

A Educação do Campo vem sendo construída pelos movimentos camponeses a partir do princípio da autonomia dos territórios materiais e imateriais ... Para a Educação do Campo desenvolvimento e educação tornaram-se indissociáveis. Para a Educação Rural, desenvolvimento é apenas um tema a ser estudado. Compreendendo o Campo como um território, a Educação precisa ser pensada para o seu desenvolvimento. Compreendendo o Rural como uma relação social do campo, a Educação é pensada como forma de inserção no modelo de desenvolvimento predominante, no caso, o agronegócio (Fernandes, 2006, citado por Gonsaga, 2009, p. 52).
Quando se fala de Educação do Campo, fala-se de uma educação própria do homem do campo, pensada pelo/com homem do campo, intercaladas aos movimentos sociais do campo que lutam incansavelmente por uma educação de qualidade neste local.

Daí a importância de se valorizar e enaltecer o trabalho, a cultura, as relações sociais, a convivência do homem do campo no currículo educacional do campo, uma vez que estes são princípios educativos. $\mathrm{O}$ trabalho é parte do processo educativo na vida de um sujeito do campo, porquanto, deve ser entrelaçado no processo de ensino-aprendizagem, para que o educando se sinta integrado nesse processo, dandolhe autonomia dentro da sala de aula e no seu convívio social.

Toda a desconstrução do espaço rural colocando a cidade como o melhor lugar para se viver faz com que o campo seja esquecido pelos órgãos públicos. Não há atendimento de saúde, saneamento básico e a educação, por sua vez, quando existe não é de boa qualidade.

Arroyo e Fernandes (1999) alertam que é preciso ter outro olhar sobre o educando, é necessário que o educador valorize o que este estudante traz de importante, suas experiências, histórias e lutas. Já Fernandes afirma que o campo é: 
... lugar de vida, onde as pessoas podem morar. Trabalhar, estudar com dignidade de quem tem o seu lugar, a sua identidade cultural. O campo não é só o lugar da produção agropecuária e agroindustrial, do latifúndio e da grilagem de terras. O campo é espaço e território dos camponeses e dos quilombolas. É no campo que estão às florestas, onde vivem as diversas nações indígenas. Por tudo isso, o campo é lugar de vida e, sobretudo de educação. (Fernandes, 2004, p. 137).

Há a necessidade de pensar currículos das escolas rurais elaborados de acordo com a realidade do aluno, valorizando identidades e costumes regionais. Considerando este aspecto, o estudo buscou identificar e compreender as dificuldades enfrentadas pelos educadores e educandos que vivenciam a realidade das classes multisseriadas nas escolas da área rural do município de Arraias-TO. Para tanto, foram entrevistados professores e alunos.

Apesar das representações negativas e dos estereótipos que têm recaído sobre as escolas de turmas multisseriadas, seus professores e seus alunos, outros olhares parecem apontar para uma nova visão sobre estas escolas, em que aquilo que até então foi enxergado como um problema pode agora ser entendido como solução e elas passam a ser consideradas, inclusive, como uma "escola portadora de futuro" (Amiguinho, 2007).
Trabalhos produzidos recentemente, a exemplo de Pinho (2004), Hage (2005), Antunes-Rocha e Hage (2010), Moura e Santos (2012), Souza (2014), Souza e Santos (2014), Sousa (2015), têm demonstrado que nas escolas de turmas multisseriadas, apesar das condições precárias, do escasso material, da formação que poderíamos considerar insuficiente de seus professores, "nascem pistas para se pensar alternativas curriculares que consideram a diferença como possibilidade de aprendizagem" (Pinho, 2004, p. 3), pois, em muitas delas acontece um trabalho de qualidade, com aprendizagem significativa por parte dos alunos.

Ao longo do estudo, verificou-se que o município de Arraias não possui o que se considera uma educação do campo, mas, sim, uma educação rural. Para se caracterizar uma educação do campo, deve ser pensada e organizada pelos povos do campo e atender aos anseios dos camponeses.

Por enquanto, a educação rural se configura uma educação na área rural, por não ser próprio das comunidades rurais, não ser pensada a partir delas, por elas, e com elas, desconsidera o contexto e, assim, transporta o modelo da cidade para o campo. É uma educação que existe no campo, mas é pensada por outros agentes, no caso do município, organizada pela Secretaria Municipal de Educação. 


\section{A Educação no Campo na visão de professores e alunos}

Analisar, a partir das memórias docentes, as práticas pedagógicas empreendidas pelos professores de turmas multisseriadas, com vistas a extrair repertórios e táticas que demonstrem o contexto da multissérie é o objetivo desta seção do artigo.

Rememora-se que este artigo é um exercício da disciplina História, Memória e Educação realizada no segundo semestre do ano de 2014. Simultaneamente, neste mesmo período os campi da Universidade Federal do Tocantins (UFT) em Arraias e Tocantinópolis passaram a oferecer vagas para cursos regulares de Licenciatura em Educação do Campo. Dois projetos da Universidade foram aprovados dentro de um edital que contemplou 40 instituições de ensino em todo o país - o Programa de Apoio à Formação Superior em Licenciatura em Educação do Campo (Pronacampo), iniciativa do Ministério da Educação (MEC), por intermédio da Secretaria de Educação Superior (SESU), Secretaria de Educação Profissional e Tecnológica (SETEC) e da Secretaria de Educação Continuada, Alfabetização, Diversidade e Inclusão (SECADI). (Carrara, 2012)

Segundo dados do Programa Nacional de Educação na Reforma Agrária
- PRONERA (Brasil, 2004), no que se refere à educação entre os assentados, a Região Norte tem 390.752 famílias assentadas. Apresenta um índice médio de pessoas não alfabetizadas de 14,74\%; 44,89\% têm nível de escolaridade de $1^{\mathrm{a}}$ a $4^{\text {a }}$ série e apenas $27,41 \%$ cursaram o nível fundamental completo. $6,72 \%$ têm o ensino médio incompleto; $4,99 \%$ completaram o ensino médio e menos de $1 \%$ completou algum curso de nível superior ou está cursando (Brasil, 2004). Já a pesquisa realizada pelo Instituto Nacional de Colonização e Reforma Agrária INCRA (PRONERA-TO) em 2010, nos projetos de assentamentos, constatou-se que dos $100 \%$ dos assentados/as, 44\% tinham 18 anos, sendo que destes $12,3 \%$ frequentavam a escola, $87,7 \%$ estavam fora da escola e $21,18 \%$ tinham escolaridade do $5^{\circ}$ até ao $9^{\circ}$ ano e apenas 7,6\% concluíram o ensino médio (Brasil, 2017). Nesse sentido, o índice de escolaridade no Estado do Tocantins é baixo, e as políticas públicas educacionais têm ocorrido de forma descontinuada e, muitas vezes, não atendem a perspectiva dos jovens camponeses, por não considerar o lugar, a cultura e a forma de produção do campo como elementos essenciais à educação.

Diante desta demanda, o Campus de Arraias desenvolveu um Grupo de Estudos e Pesquisas em Educação do Campo onde se articulou ações de Ensino, Pesquisa e 
Extensão na área da Educação do Campo e foi contemplado com o projeto intitulado: "A Educação do Campo em foco: uma análise interdisciplinar da realidade das escolas rurais no Sudoeste do Tocantins", aprovado em 2010/ CAPES/MEC.

No período de 2011 a 2013, a Universidade Federal do Tocantins, mais especificamente, o Campus de Arraias, apresentou o Projeto Político Pedagógico para o Curso de Licenciatura em Educação do Campo, que se destinou à formação inicial de 120 (cento e vinte) discentes oriundos da área rural, por ano, para atuarem nas escolas do campo situadas em contextos socioculturais diversificados. Nesse projeto, as justificativas e as diretrizes curriculares organizativas para o desenvolvimento do Curso eram para o atendimento das políticas públicas para a Educação do Campo, bem como solucionar as proposições dos Movimentos Sociais e Sindicais, Fórum Estadual de Educação do Campo e das secretarias estaduais e municipais de educação.

A história oral, metodologia utilizada nesta pesquisa, consiste em realizar entrevistas gravadas com pessoas que testemunham acontecimentos, conjunturas, instituições, modos de vida ou outros aspectos da história da educação. É uma prática de apreensão de narrativas feitas através do uso de meios eletrônicos e destinadas a recolher testemunhos, promover análises de processos sócioeducacionais do presente e facilitar o conhecimento do meio imediato (Santos \& Azevedo, 2017).

Os depoimentos destacam a diversidade de metodologia, o desempenho profissional e o contexto escolar. Roteiro: Como se constituíram professores de turmas multisseriadas? Que formação possuem? Em que condições exercem a docência? Que práticas empreendem? Como organizam o espaço-tempo em sala de aula num contexto pedagógico marcado pela pluralidade? Como se relacionam com alunos, pais, docentes, Secretaria Municipal de Educação e comunidade? Que modos de fazer caracterizam a docência nestes espaços? Que lembranças do fazer pedagógico lhe marcaram ao longo desta trajetória?

A opção pela história oral possibilitou conhecer os docentes e discentes como sujeitos e como se veem dentro dessa história. Tramas de experiências e valores, de saberes, de formas e de recursos que passamos a relatar.

\section{Compreendendo os desafios em trabalhar com classes multisseriadas}

Sobre a pergunta: como organizam o espaço-tempo em sala de aula num contexto pedagógico marcado pela pluralidade? a professora Rocha destacou 
que há necessidade de dedicação especial para cada aluno, principalmente na fase de alfabetização. O tempo para trabalhar com várias séries reunidas é um dos desafios mais difíceis de enfrentar, segundo os professores entrevistados. O período é considerado curto e o número de alunos, em contrapartida, é grande. Veja o que dizem os entrevistados:

O desafio é o tempo, porque você tem que ter tempo para cada aluno, o tempo eu acho meio que corrido, por mais que seja pouco aluno. Mas você tem que ter o tempo é a base, né?!

A alfabetização é a base porque tem que ser trabalhado perfeito, é como se você construísse uma casa né, então a alfabetização pra mim é a base, então assim o tempo é pouco, eu acho pouco, não é como na cidade os meninos aqui não tem uma creche né, ... vão diretamente pra escola, só que, tudo que eu posso fazer né, é sanar essa dificuldade, eu faço. Então é assim o tempo que eu acho pouco, para mim, eu tenho que ter tempo para todos, então o tempo eu acho pouco, porque quando to ensinando no primeiro ano o segundo tia... o terceiro tia... 'Então assim o tempo pra mim eu acho pouco.' (Rocha, 2014).

Como foi citado anteriormente, o período de 2011 a 2013 foi de reivindicações para a implantação da Licenciatura em Educação do Campo em Arraias. A maioria dos alunos do entorno do Campus da UFT do referido município faz o curso de Pedagogia ou Matemática.

Uma parte dos docentes entrevistados terminou há pouco tempo a própria formação e o contato que teve com sala de aula foi pequeno. Segundo Hage (2010), o total desconhecimento do contexto da multisseriação, a falta de compreensão mais abrangente desse processo, muitos professores e professoras das escolas com turmas multisseriadas organizam o seu trabalho pedagógico sob a lógica da seriação, desenvolvendo suas atividades educativas referenciados por uma visão de "ajuntamento" de várias séries, que os obriga a elaborar tantos planos de ensino e estratégias de avaliação diferenciadas quanto forem às séries com as quais trabalham, envolvendo estudantes da pré-escola e Ensino Fundamental concomitantemente.

Olha, é um desafio muito grande porque, eu particularmente que recém-saído da faculdade e também não imaginava que eu poderia trabalhar com sala de aula, enfrentei o seguinte: porque trabalhar com multisseriada é muita turma junta ali, é muito... os alunos que vivem a realidade local ... eles são muito deficientes, em questão principalmente de leitura, de escrita, quer dizer escrever e interpretar, ler, escrever e tudo. Então o desafio é você lidar no meu caso que trabalho com quatro séries, lidar com quatro séries ao mesmo tempo, porque é complicado e ao mesmo tempo em que você tem que cuidar do comportamento do aluno você já tem que cuidar também do exercício que você tem que passar pra ele, tem que ter o cuidado até da linguagem que você deve transmitir a eles, por que de repente eles também não raciocinam né, esses são os principais 
desafios pra trabalhar com escola multisseriada que estou encontrando". (Santos, 2014).

Além disso, é preciso entender e articular o ensino nas salas multisseriadas e, segundo os relatos dos professores, não houve nenhuma preparação prévia para esta realidade.

É bem difícil, sabe por quê? Por que assim como eu já trabalhei com uma turma só que não multisseriada, então se torna bem mais fácil pra você acompanhar aquele aluno que tem dificuldade, entendeu? E na sala multisseriada isso já se torna bem mais difícil porque até pro reforço é difícil porque você tem alunos com dificuldades quase todas as turmas, entendeu? ...então você tem que dar uma atenção bem maior pra aquele aluno, e na sala mesmo assim no normal de sala de aula você não tem isso, por que toda hora um chama de um lado outro chama, entendeu? Então acaba tirando a concentração daquele que esta com dificuldade, então com isso tem que levar pro reforço então pra hora do recreio chama aquele aluno e senta pra tentar sanar as dúvidas deles, entendeu? E contar com o apoio da família que é o que eu sempre corro atrás (Silveira, 2014).

Apesar das dificuldades, os docentes enxergam aspectos positivos também, no cotidiano das salas multisseriadas, que serão apresentados a seguir.

\section{Os aspectos positivos na multisseriação}

A presença da escola na comunidade rural é o principal motivo para os docentes entrevistados considerarem positiva a classe multisseriada. Eles destacaram ainda o fato de que os alunos valorizam muito ter um professor perto de casa, portanto, têm prazer em ir à escola. Isso serve de inspiração e incentivo para manutenção, investimento e a valorização da escola do campo e, principalmente, a valorização do professor.

O bom ... é quando você trabalha... por exemplo, ... com os alunos do terceiro ano, o segundo ano uma série adiantada o outro ta ali, então assim às vezes quando você... ta lá na frente 'ah eu vi isso lá no terceiro ano, quando eu tava falando no terceiro ano, falou sobre isso'. Então isso é bom acaba acompanhado algo da outra turma também (Rocha, 2014).

O ensino multisseriado representa um aliado da aprendizagem, no contexto dialógico, pois valoriza a diversidade e a heterogeneidade. Por outro lado, há grandes dificuldades para a contratação e permanência de professores.

Olha o bom é porque as crianças vêm mesmo assim com aquele empolgamento de estudar, porque aqui pra achar professor não é fácil, inclusive aqui já veio comigo a segunda pessoa, a outra menina veio não ficou, ficou três dias só. Então assim, eles têm empolgamento de vir porque tem um professor ele dá valor, os alunos dão valor no professor. (Santos, 2014)

De bom é por que é nosso meio por isso, a gente gosta de fazer, trabalhar com a turma, a gente trabalha de pouquinho a pouquinho pra ver o crescimento de cada aluno, isso dá prazer (Silveira, 2014). 
Nota-se que os elementos caracterizados como bons fundamentam-se no prazer que os professores têm em ensinar e, mais ainda, ver o aluno aprendendo. Daí percebe-se que o ensinoaprendizagem está acontecendo. O aluno fica feliz por ter escola e o professor fica feliz por desenvolver sua função de modo que o aluno consegue aprender.

\section{Como se constrói a organização e o planejamento para as classes multisseriadas}

Os docentes seguem o planejamento orientado elaborado juntamente com a Secretaria Municipal de Educação de Arraias (TO). A partir deste planejamento, elaboram o plano diário de aulas. Todos os professores seguem o planejamento orientado, mas aqueles que estudaram em uma classe multisseriada têm mais facilidade para lidar com tal realidade.

Os planos de aula são feitos diariamente por alguns professores, outros preferem fazê-lo semanalmente. Para cada série é feito um plano de aula. Nota-se pelo que os professores disseram que isso torna ainda mais difícil a prática docente, pois tem que desenvolver vários planos em uma única turma. É um professor sozinho para orientar toda a turma.

Para desenvolver os conteúdos, utilizam a seguinte metodologia: trabalha- se com o $1^{\circ}$ ano, logo após com o $2^{\circ}$, depois o $3^{\circ}$ e assim sucessivamente.

Eu estipulo o tempo, quando eu estou explicando para o primeiro ano, o segundo tá respondendo a atividade rodada, eu sento um pouquinho com eles, explico, pego o trabalho e assim sucessivamente, aí quando eu termino do primeiro ano eu já vou pro terceiro, dando um tempo pro segundo. Dessa forma que é trabalhado (Rocha, 2014).

Cada um é um, agora esse mês passado que eu deixei o do primeiro ano junto com o do segundo porque tinha um menino e uma menina assim quase igual do segundo, aí eu peguei e deixei junto, fiz só a separação assim, fiz junto e coloquei primeiro e segundo, aí na hora que vou trabalhar lá aí faço a diferença, aí divido no quadro igual divido uma parte e já ponho primeiro, mas eu ponho do quarto pra cima, mas é só divisão, aí os separo (Silveira, 2014).

Uma das docentes exemplifica como separa os temas por disciplina:

Por exemplo, Língua portuguesa, um dia eu trabalho com Língua portuguesa, eu peço pra todos os alunos, aí eles pegam... Normalmente eu começo mesmo é com leitura, aí eles fazem a leitura prévia, enquanto o quinto ano tá fazendo a leitura eu estou me direcionando para o terceiro ano, aí depois que eu termino a atividade do terceiro ano quando eles estão copiando eu vou pro segundo ano (Santos, 2014).

Outra professora afirma que, além de ministrar as aulas, exerce outras funções junto aos alunos. Torna-se mãe, psicóloga, inclusive, merendeira, quando a funcionária falta. São professores, mas fazem praticamente todas as funções 
dentro da escola. O trabalho docente nas escolas com turmas multisseriadas se configura pela sobrecarga de atividades, instabilidade no emprego e angústias relacionadas à organização do trabalho pedagógico. Nessas escolas, um único professor atua em múltiplas séries concomitantemente, reunindo estudantes da pré-escola e dos anos iniciais do ensino fundamental em uma mesma sala de aula; sendo obrigado a assumir outras funções, além da docência, ficando responsável pela confecção e distribuição da merenda, limpeza da escola, realização da matrícula e demais atividades de secretaria e de gestão (Hage, 2010).

\section{Sobre a formação dos professores que trabalham com classes multisseriadas}

Um dos problemas relatados pelos professores se refere à organização da aula e à falta de formação específica para a multisseriação. O que se percebe é que a maioria dos professores não sabe como deve ser ministrado o ensino nessas classes. O possível fracasso é atribuído ao modelo adotado, no entanto, se os professores tivessem uma preparação prévia adequada, poderiam contornar as dificuldades, compreendendo aspectos e desafios, para preparar atividades e um planejamento enriquecedor para aplicar em sala de aula.
A formação inicial do docente tem um caráter mais geral e, ao longo da atuação, os professores fazem cursos de aperfeiçoamento da prática, sem foco específico para trabalhar em uma escola de classe multisseriada. Observa-se que há a implantação do modelo seriado dentro da classe multisseriada e pelo que se percebe isto compromete o processo de ensinoaprendizagem. Tanto o professor tem dificuldade em ensinar quanto o aluno tem em aprender.

Se os professores não possuem essa capacitação, como que eles aprenderam a trabalhar com esse modelo de ensino? A partir deste questionamento os professores dão detalhes que permitem compreender como aprenderam a ensinar em uma classe multisseriada.

Olha, eu acho que já veio desde o tempo de estudo por que eu saí de uma sala multisseriada né, eu estudei nesta mesma sala, então assim isso já vem desde ... do tempo de estudo. Mas formação mesmo voltada pra multisseriação só na formação continuada e planejamento (Rocha, 2014).

$\mathrm{O}$ fato de ter estudado em uma classe multisseriada contribui para a atuação do professor porque se trata de uma realidade já experienciada.

Bom, eu já estudei em classe multisseriada quando eu morava na Lagoa da Pedra, eu estudei assim, questão de vivência, então eu aprendi 
dessa forma, não que tenha específico uma formação pra trabalhar né, numa classe multisseriada (Santos, 2014).

Eu dou conta pelo menos um pouco pelo fato de ter estudado numa classe multisseriada, mas formação especifica para multisseriada nunca tive (Silveira, 2014).

O número de Licenciaturas em Educação no Campo cresceu consideravelmente na última década e hoje passa de quatro dezenas. Instituições pelo país acreditam na proposta e participam desse processo de implantação; entre elas podemos citar a Universidade Federal do Tocantins, que oferta a Licenciatura em dois de seus campi: Arraias e Tocantinópolis. Os cursos desses campi foram criados a partir da iniciativa de um coletivo de educadores que, em resposta ao Edital Chamada Pública n ${ }^{\circ}$ 2, da SECADI, de 3 de agosto de 2012, propuseram-se a formular os Projetos Político-Pedagógicos (PPP) do Curso (Brasil, 2014).

A presença da comunidade e sua identificação com a UFT foi um fator essencial na construção da proposta educacional que valorize o seu território e os saberes do seu povo. Neste sentido, foi preciso ampliar e fortalecer ainda mais esta articulação, esta proximidade e este diálogo entre UFT-comunidade, professoraluno-pais-comunidade, não só nos momentos de integração e de festividades, mas também no planejamento das atividades e nas tomadas de decisões presentes no Projeto Político-Pedagógico do curso.

É necessário construir uma visão positiva do campo, pensar em uma formação inicial e continuada que reverta a visão negativa que se tem do campo, destaca Arroyo (2007), e complementa afirmando a necessidade de implantação de políticas de formação sintonizadas com a dinâmica social do campo, onde está implícita a afirmação de direitos à terra, à cultura e identidade e à educação.

\section{Classes multisseriadas na visão dos estudantes}

A multissérie pode ser compreendida como uma organização que possibilita o desenvolvimento de um processo educativo diferente, em que os alunos de faixas etárias e experiências diversas podem participar e criar formas coletivas de organização do conhecimento até com maior maturidade quando comparadas à metodologia seriada. Isto é, por se caracterizarem pela diversidade e por serem heterogêneas, as classes multisseriadas permitem usar esse aspecto de modo positivo, buscando, na interação e na construção de relações das diferenças, a possibilidade de uma cooperação dentro do espaço escolar, com aprendizagens significativas. Para tanto, o professor precisa organizar-se de maneira a não 
centralizar a aprendizagem em si e acreditar que a troca entre os alunos também favorece a aprendizagem.

Morin (2001) explica que a complexidade está presente em cada ser e em sua interação social e reafirma que, por mais que se busque a homogeneidade por níveis de aprendizagem, a diversidade estará presente. Nesse sentido, a troca de experiências e a valorização do sujeito e de sua cultura são desconsideradas no processo pedagógico, uma vez que a separação em classes homogêneas vem reforçar os privilégios daqueles que têm melhores condições. Mesmo assim, por mais que se busque a homogeneidade, em sua essência, isso não é possível.

No entanto, além dos docentes, é preciso analisar também o contexto da educação na perspectiva do estudante. Alunos relataram suas dificuldades em sala, o que é confirmado no relato dos professores.

Às vezes eu preciso da ajuda da professora e ela tá ocupada ensinando meus outros colegas de outra série, aí eu deixo pra lá mesmo, é muito ruim (Andrade, 2014).

O aluno não percebe que até mesmo no ensino seriado a professora não tem tempo para atender a todos os alunos individualmente. Não sendo apenas uma exceção do ensino multisseriado. $\mathrm{O}$ comportamento dos alunos é afetado.
Enquanto a professora ensina um aluno, o outro fica disperso.

Assim, eu estudo no primeiro ano e quando às vezes a professora tá ensinando o segundo ano eu não consigo prestar atenção nas minhas tarefas porque fico escutando a professora ensinando meus outros colegas, todo mundo junto (Souza, 2014).

$\mathrm{O}$ 'todo mundo junto' nem sempre agrada. Os alunos buscam um atendimento especial nem sempre possibilitado por este tipo de ensino-aprendizagem, pois "Não, é muita série junta, às vezes não entendo as tarefas" (Andrade, 2014).

$\mathrm{Na}$ perspectiva de Hage (2005), a multissérie oportuniza o apoio mútuo e a aprendizagem compartilhada, a partir da convivência mais próxima estabelecida entre estudantes de várias séries na mesma sala de aula, o que em determinados aspectos é considerado salutar. Outro aluno faz uma ressalva, dizendo que gosta "mais ou menos, eu gosto mais é porque estudo na roça, perto do meu pai e minha mãe" (Souza, 2014).

Eles também idealizam a escola que gostariam que fosse implantada no campo. "Que fosse igual da cidade, grandona, e cada um na sua sala, né”? (Andrade, 2014). O depoimento é confirmado por outro estudante, ao dizer como gostaria que fosse a sua escola: "igual daqui de Arraias para 
ter mais espaço pra gente brincar" (Souza, 2014).

O desejo é ter espaço próprio e separado nas salas de aula. E a falta desta estrutura adequada acaba contribuindo para a evasão escolar.

\section{Considerações finais}

A educação ultrapassa as barreiras da sala de aula e o mundo interior da criança porque abrange as relações sociais, o convívio, a interação e o mundo. E todo esse aparato deve ser contemplado no processo ensino-aprendizagem favorecendo a discussão da temática proposta neste estudo: uma educação de qualidade.

Nas palavras de Barros et al. (2010):

Essa situação advém de uma compreensão universalizante de currículo, orientada por uma perspectiva homogeneizadora, que sobrevaloriza uma concepção mercadológica e urbanocêntrica de vida e de desenvolvimento e que desvaloriza os saberes, os modos de vida, os valores e concepções das populações que vivem e são do campo, diminuindo sua autoestima e descaracterizando suas identidades. (Barros et al., 2010, p. 28).

A implantação de políticas públicas, a construção de uma nova proposta pedagógica, a elaboração de um currículo que contemple as relações sociais dos sujeitos do campo nas palavras de Moraes et al. (2010):

... implica ouvir os sujeitos do campo e aprender com suas experiências de vida, trabalho, de convivência e de educação; oportunizá-los o acesso à informação, à ciência e às tecnologia, sem hierarquizar os conhecimentos, valores, ritmos de aprendizagem. Implica também realizar uma 'escuta sensível' ao que os professores e estudantes vêm realizando no cotidiano da escola... Enfim, repensar as práticas e formular novas propostas sintonizadas com a realidade dos sujeitos do campo, ou seja, do lugar dos sujeitos do campo, sem apartá-los do mundo global, do contexto urbano, com os quais o território do campo interage continuamente, constituindo-se em sua identidade/subjetividade, a partir dessa interação (Moraes et al., 2010, p. 407).

Para conhecer as necessidades das comunidades que vivem no campo, é necessário dar-lhes voz, inserir-se no seu meio. Não basta somente criar escolas no campo e ter professores nessas escolas. É preciso mais: que professores e alunos carecem de condições estruturais adequadas para estudar e se manter no campo, em seu lugar de sobrevivência.

Uma escola rural, parafraseando Marinho (2008, p. 64), “... sem estrutura, como garantias de estabilidade, prédio próprio, residência para os professores, campo de ensaios e de experimentação e com docentes inexperientes, não pode oferecer esperança de transformação do indivíduo ...”. 
A Educação do Campo está longe de se tornar prioridade nas agendas públicas, principalmente, no que diz respeito às políticas de desenvolvimento rural sustentável. A cada dia, novos agentes surgem engajados nessa luta. Percebe-se, então, que o campo já não está mais sozinho, que possui voz ativa mediada pelo ingresso de novos sujeitos que perceberam a necessidade de fortalecer o discurso e as ações em favor dos povos do campo.

Nesta luta conhecer o campo é indispensável para a transformação do mesmo, inserir-se no contexto, na vida do camponês, conhecer a escola, o aluno, o professor e toda a realidade faz-se refletir sobre a dignidade humana, sobre a importância da educação na vida de um sujeito. É necessário perceber o valor que estes possuem, que merecem atenção, benefícios, que favoreça uma vida melhor, respeito, valorização. E muito mais que isso, o compromisso dos órgãos responsáveis pelo desenvolvimento e crescimento de fazer valer todos esses direitos.

É visto que os professores do meio rural no município de Arraias são comprometidos com a educação. Não se pode falar que estão nestas escolas por causa do salário que recebem. Há a necessidade de uma maior valorização financeira, sendo necessário um esforço maior para a permanência desses professores no meio rural com um salário mais digno.

Percebeu-se ainda a carência dos povos do campo em atendimento e em informação. Falta dignidade a esses povos, falta lazer, comodidade, respeito. Uma educação de qualidade é uma realidade para um futuro muito distante, falta muito. O meio rural no município está realmente esquecido. O "sertanejo" arraiano, expressão utilizada pela população local, referindo-se ao homem que vive no sertão (campo), necessita urgentemente de atendimento em todos os aspectos no que diz respeito à condição de vida humana.

Conscientes da realidade do sistema educacional brasileiro, embora o modelo de multissérie permaneça sendo alvo de debates e muitas divergências, especialmente quanto a sua eficiência no processo de ensino-aprendizagem e em função das especificidades e dificuldades que o envolvem é preciso considerar que, as escolas multisseriadas ainda encontramse presentes em todas as regiões do Brasil e revelam-se como protagonistas na garantia do direito ao acesso à Educação para grande parte das crianças e trabalhadores do campo e, portanto, é preciso tratá-las como aliadas e estimular o desenvolvimento de estudos e de pesquisas que colaborem para a oferta de uma educação de qualidade. 
Utilizar as entrevistas como instrumento de pesquisa permitiu-nos extrair uma importante quantidade de dados e informações que deram maiores subsídios à pesquisa. Foi possível perceber mais claramente como os professores e alunos enxergam a realidade em que estão inseridos e identificar, por conseguinte, os desafios urgentes que precisam ser alcançados para garantir educação integradora e de qualidade para centenas de estudantes que vivem distantes das zonas urbanas no Tocantins, e no Brasil.

\section{Referências}

Alberti, V. (2004). Manual de História Oral. Rio de Janeiro, RJ: Editora FGV.

Amiguinho, A. (2007). A escola e o futuro do mundo rural. Lisboa, PT: Fundação Calouste Gulbenkian.

Andrade, B. T. (2014). Entrevista concedida a Samara Caldas Franco. Arraias-TO.

Antunes-Rocha, M. I., \& Hage, S. M. (Orgs.). (2010). Escola de Direito: Reinventando a escola multisseriada. Belo Horizonte, MG: Autêntica.

Arroyo, M. G. (2007). Políticas de formação de educadores(as) de campo. Cad. Cedes, 27(72). DOI: http://dx.doi.org/10.1590/S010132622007000200004

Arroyo, M. G., \& Fernandes, B. M. (1999). A educação básica e o movimento social do campo. Brasília, DF: Articulação Nacional por uma Educação do Campo.
Barros, O. F. et al. (2010). Retratos de realidades das escolas do campo: multissérie, precarização, diversidade e perspectivas. In Antunes-Rocha, M. I., Hage, S. M. (Orgs.). Escolas de Direito: Reinventando a escola multisseriada (pp. 25-33). Belo Horizonte, MG: Autêntica.

Brasil. (2004). Manual de Operações do Programa Nacional de Educação na Reforma Agrária - PRONERA. Brasília, DF: MDA/INCRA.

Brasil. (2014). Resolução do Conselho de Ensino, Pesquisa e Extensão - CONSEPE, $n .^{\circ}$ 05/2014. Dispõe sobre a aprovação do Projeto Pedagógico do Curso (PPC) de Licenciatura em Educação do Campo (Campus de Arraias). Palmas, TO: UFT. Recuperado de: http://download.uft.edu.br/?d=2b2b330c2a4c-4065-93d3-dc1e7975728d:052014\%20-

Brasil. (2017). Curso de Aperfeiçoamento Escola da Terra. Palmas, TO: UFT. Recuperado de: https://docs.uft.edu.br/share/s/szhYPpW_T SC7Sx613E9x9g

Carrara, J. (2012). UFT terá licenciatura em Educação no Campo. Recuperado de: http://ww2.uft.edu.br/ultimasnoticias/10324-2012-12-uft-teralicenciatura-em-educacao-do-campo

Fernandes, B. M. (2004). Diretrizes de uma Caminhada. In Arroyo, M. G., Caldart, R. S., \& Molina, M. C. (Orgs.). Por uma educação do campo (pp. 113146). Petrópolis, RJ: Vozes.

Gonsaga, E. A. (2009). Pedagogia da Terra - o curso de licenciatura em educação do campo em Minas Gerais. (Dissertação de Mestrado). Universidade Federal Fluminense, Rio de Janeiro.

Hage, S. M. (2004). Educação do Campo na Amazônia: retratos da realidade das 
escolas multisseriadas no Pará. In Reunião GPT Educação do Campo. Brasília, DF.

Hage, S. M. (2005). GEPERUAZ: aspectos significativos de sua criação, identidade e abrangência. In Hage, S. M. (Org.). Educação do campo na Amazônia: Retratos de realidade das escolas multisseriadas no Pará (pp. 22-30). Belém, PA: M. M. Lima Ltda.

Hage, S. M. (2010). Escolas multiseriadas. In Oliveira, D. A., Duarte, A. M. C., \& Vieira, L. M. F. (Orgs.). Dicionário: trabalho, profissão e condição docente. Belo Horizonte, MG: UFMG/Faculdade de Educação, CDROM.

Marinho, E. R. (2008). Um olhar sobre a educação rural brasileira. Brasília, DF: Universa.

Menezes, E. T., \& Santos, T. H. (2002). "Classes multisseriadas" (verbete). Dicionário Interativo da Educação Brasileira - EducaBrasil. São Paulo, SP: Midiamix Editora. Recuperado de: www.educabrasil.com.br/dicionario

Moraes, E. et al. (2010). Transgredindo o paradigma (multis)seriado nas escolas do campo. In Antunes-Rocha, M. I., \& Hage, S. M. (Orgs.). Escolas de Direito: Reinventando a escola multisseriada (pp. 399-415). Belo Horizonte, MG: Autêntica.

Morin, E. (2001). A religação dos saberes: $o$ desafio do século XXI. Trad. Flavia Nascimento. Rio de Janeiro, RJ: Bertrand Brasil.

Moura, T. V., \& Santos, F. J. S. (2012). A pedagogia das classes multisseriadas: um olhar sobre a prática pedagógica dos/as professores/as da roça do município de Amargosa-BA. In Souza, E. C. (Org.). Educação e Ruralidades: memórias $e$ narrativas (auto) biográficas. (pp. 265293). Salvador, BA: EDUFBA.

Pinho, A. S. T. (2004). A heterogeneidade fundante das classes multisseriadas do meio rural: entre a persistência do passado e as imposições do presente. (Dissertação de Mestrado). Universidade do Estado da Bahia, Salvador.

Piza, F., \& Sena, L. B. (2001). PMG 3 Escola Ativa. Salto para o Futuro. Recuperado de: www.tvebrasil.com.br/saltoparaofuturo/bol etim2001

Rocha, T. C. S. (2014). Entrevista concedida a Samara Caldas Franco. Arraias-TO.

Santos, M. A. R. (2014). Entrevista concedida a Samara Caldas Franco. Arraias-TO.

Santos, J. S., \& Azevedo, S. (2017). Vozes docentes no Pafor Tocantino. In Auler, I., \& Pinho, M. J. (Orgs.). Perspectivas da formação docente: o programa Pafor em foco (pp. 283-300). Palmas, TO: EdUFT.

Sousa, R. C. (2015). Multisseriação $e$ profissão docente: condições de trabalho docente de professoras do Território de Identidade do Baixo Sul. (Dissertação de Mestrado). Universidade do Estado da Bahia, Salvador.

Souza, E. C., \& Santos, F. J. S. (2014). Educação rural e multisseriação: rompendo silêncios e indicando horizontes. In Silva, M. A., \& Cunha, C. (Orgs.). Educação básica: políticas, avanços e pendências (pp. 315-345). Campinas, SP: Autores Associados.

Souza, J. H. M. (2014). Entrevista concedida a Samara Caldas Franco. Arraias-TO. 
Silveira, A. G. (2014) Entrevista concedida a Samara Caldas Franco. Arraias-TO.

Recebido em: 30/06/2017

Aprovado em: 30/07/2017

Publicado em: 03/05/2018

\section{Como citar este artigo / How to cite this article /} Como citar este artículo:

APA:

Santos, J. S., \& Franco, S. C (2018). As multisséries no Campo de Arraias-TO: memórias. Rev. Bras. Educ. Camp., 3(1), 223-244.

\section{ABNT:}

SANTOS, J. S.; FRANCO, S. C.; As multisséries no Campo de Arraias-TO: memórias. Rev. Bras. Educ. Camp., Tocantinópolis, v. 3, n. 1, p. 223244, 2018.

\section{ORCID}

Jocyléia Santana dos Santos

(iD) http://orcid.org/0000-0003-2335-121X

Samara Caldas Franco

iD http://orcid.org/0000-0003-0268-2589

Declaramos para os devidos fins que Samara Caldas Franco confeccionou o artigo na disciplina História, Memória e Educação. A professora Jocyléia Santana dos Santos foi responsável pela análise e interpretação dos dados e revisão do conteúdo para versão final a ser publicada. 